\title{
Thirty years of Continuity and Change
}

Continuity and Change first appeared in 1986 and enters its thirtieth year in 2015. To help us celebrate this landmark, Lloyd Bonfield, one of the journal's founding editors, reflects in this issue on the origins and development of the journal. The editors are most grateful to Lloyd for his interesting and enjoyable essay.

We are also marking the thirtieth anniversary with a special online collection of past articles from the journal. The editorial team, in collaboration with the editorial board, has selected ten 'classic' articles which we think are among the most representative and influential published in the journal over the last three decades. To view the articles, please use this link:

http://journals.cambridge.org/con30

The articles in this online 'anniversary issue' will be freely available from 1 January to 31 December 2015. Please feel free to circulate and share the link.

May we take this opportunity to thank everyone who has supported the journal since 1986 . Here's to another thirty years!

CHRIS BRIGGS University of Cambridge

SUSAN LEONARD University of Michigan

JULIE MARFANY

Durham University

MARY LOUISE NAGATA

Francis Marion University 